\title{
Editorial
}

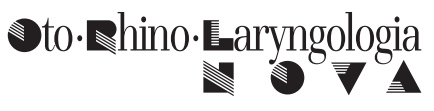

Otorhinolaryngol Nova 2002-03;12:265

DOI: $10.1159 / 000083113$

\section{The End ... or Just a Change?}

Dear readers,

We regret to inform you that this is the last issue of ORL Nova. Indeed, for many reasons briefly analysed below, we estimate that the efforts necessary to maintain the journal might better serve the scientific community by merging ORL Nova with another journal published by Karger, ORL, Journal for Oto-Rhino-Laryngology and Its Related Specialties.

As chief editors of ORL Nova, supported by prominent specialists in the field of otolaryngology and its related fields as associate editors, our ambition was not only to publish excellent manuscripts but also to favour discussions about the many unresolved topics in all fields of the specialty. We thought that publishing ORL Nova in three languages, English, German and French, would represent an opportunity to facilitate exchanges between academic centres and practitioners working under different cultural, social, economical, and geographical conditions.

Unfortunately, it has turned out that the trilingual character of the journal was rather a burden for its promotion in Europe and the rest of the world. The scientific level reached by the journal was honoured as it was quoted in the Current Contents. In spite of this success, the distribution of the journal remained insufficient to have it referenced in Medline. This provoked authors to submit their manuscripts for publication to other journals, where they can be found more easily and therefore cited in subsequent works by other researchers. That is why we would like to thank all the authors who submitted manuscripts to ORL Nova in spite of these limitations.
In particular, we would like to express our deepest gratitude to the long list of renowned experts who participated to the debates appearing in the 'Controversial Issues' in providing outstanding manuscripts. In these issues, recognized experts known to uphold a specific point of view were selected for their first-hand knowledge of a chosen topic and invited to prepare a manuscript, which was then submitted for comments to other authors. All the commentaries are published along with the invited papers.

These debates will continue, edited by the same persons, but from now on will appear in ORL, Journal for Oto-Rhino-Laryngology and Its Related Specialties as 'Controversies in ORL'. The next debate will be devoted to 'Tinnitus'. We hope these changes will make the debates accessible to a larger number of readers and encourage invited experts to participate.

In conclusion, ORL Nova will no longer appear, but part of it will be transferred to ORL, Journal for Oto-Rhino-Laryngology and Its Related Specialties. Our main purpose to open a forum for discussions remains intact. We hope the interest of the readers will also be maintained.

Jean-Philippe Guyot, Geneva Rudolf Häusler, Berne 